\title{
Erratum regarding missing Declaration of Competing Interest statements in previously published articles
}

Declaration of Competing Interest statements were not included in published version of the following articles that appeared in previous issues of Clinical Epidemiology and Global Health. Hence, the authors of the below articles were contacted after publication to request a Declaration of Interest statement:

1. "Mental health status of Farmers in Maharashtra, India: A study from farmer suicide prone area of Vidarbha region" [Clinical Epidemiology and Global Health, 2020; 8 : 684-688] DOI: htt ps://doi.org/10.1016/j.cegh.2020.01.002

2. "Prevalence and antimicrobial sensitivity pattern of bacteria causing urinary tract infection; study of a tertiary care hospital in North India" [Clinical Epidemiology and Global Health, 2020; 8 : 890-893] DOI: https://doi.org/10.1016/j.cegh.2020.02.018

3. "Association of Secreted Frizzled Related Protein 4 with Type 2 Diabetes Mellitus and its complications: A South Indian hospital based case control study" [Clinical Epidemiology and Global Health, 2021; 9 : 171-174] DOI: https://doi.org/10.1016/j.cegh 2020.08.009

4. "Outbreak of acute diarrhoeal disease attributed to consumption of faecal contaminated water supplied through damaged pipelines in Thiruper, Tiruvallur district, Tamil Nadu, India, 2016" [Clinical Epidemiology and Global Health, 2021; 10 : 100701] DOI: https://doi.org/10.1016/j.cegh.2021.100701
5. "Gender differential and regional disparity of disability-free lifeexpectancy among disable in India" [Clinical Epidemiology and Global Health, 2020; 8 : 818-827] DOI: https://doi.org/10.1016 j.cegh.2020.02.007

6. "Public perception and preparedness for the pandemic COVID 19: A Health Belief Model approach" [Clinical Epidemiology and Global Health, 2020; 9: 41-46] DOI: https://doi.org/10.1016/j. cegh.2020.06.009

7. "Prevalence of atopic disorders in 10-15 years age group students from Kasaragod district, Kerala: A cross-sectional study" [Clinical Epidemiology and Global Health, 2021; 12: 100823] DOI: htt ps://doi.org/10.1016/j.cegh.2021.100823

8. "Prenatal health-related quality of life assessment among Hungarian pregnant women using PROMIS-43" [Clinical Epidemiology and Global Health, 2021; 9: 237-244] DOI: https://doi. org/10.1016/j.cegh.2020.09.005

9. "Meta-MUMS DTA: Implementation, validation, and application of diagnostic test accuracy software for meta-analysis in radiology" [Clinical Epidemiology and Global Health, 2021; 9: 310-325] DOI: https://doi.org/10.1016/j.cegh.2020.10.004

10. "Households' responses on medical pluralism: Dynamics and determinants of access to traditional medicines in India" [Clinical Epidemiology and Global Health, 2021; 12: 100880] DOI: htt ps://doi.org/10.1016/j.cegh.2021.100880

DOIs of original article: https://doi.org/10.1016/j.cegh.2020.08.009, https://doi.org/10.1016/j.cegh.2020.10.004, https://doi.org/10.1016/j.cegh.2021. 100701, https://doi.org/10.1016/j.cegh.2020.01.002, https://doi.org/10.1016/j.cegh.2020.02.018, https://doi.org/10.1016/j.cegh.2020.06.009, https://doi.org/ 10.1016/j.cegh.2021.100880, https://doi.org/10.1016/j.cegh.2020.02.007, https://doi.org/10.1016/j.cegh.2021.100823, https://doi.org/10.1016/j.cegh.2020.09. 005.

https://doi.org/10.1016/j.cegh.2022.101002 